\title{
The Study of Tadalafil and Tamsulosin as Monotherapy for Lower Urinary Tract Symptoms Due to Benign Hyperplasia of Prostate
}

\author{
Sudhakaran Selvaraj ${ }^{1}$, Senthil Kumar Sivalingam² \\ ${ }^{1}$ Department of Urology, Government Chengalpattu Medical College and Hospital, Chengalpattu, Tamilnadu, India. \\ ${ }^{2}$ Department of Urology, Government Chengalpattu Medical College and Hospital, Chengalpattu, Tamilnadu, India.
}

\section{ABSTRACT}

\section{BACKGROUND}

BPH is the most common benign tumour in men and its incidence increases with age. BPH is a histological diagnosis which is identified by non-malignant hyperplasia of prostatic tissue due to smooth cell and epithelial cell proliferation. Although the current medical therapy, alpha 1 blocker alone or in combination with 5 alpha reductase inhibitors, for BPH-LUTS is effective, it has potential side effects on sexual function like retrograde ejaculation/anejaculation. BPH refers to proliferation of smooth muscle and epithelial cells within the prostate gland mainly involving transitional zone. The aim of this study is to compare Tadalafil and Tamsulosin as monotherapy in the treatment of BPH.

\section{METHODS}

We analysed 60 patients of BPH (Benign Prostatic Hyperplasia) with LUTS (Lower Urinary Tract Symptoms) with baseline parameters as International Prostate Symptom Score (IPSS), QMAX (maximum urinary flow velocity), PVR (Post Voidal Residual urine volume), for a period of 6 months. They were divided in to two groups, one group receiving only alpha blockers, other group receiving only PDE -5 inhibitor (Phosphodiesterase type 5 inhibitor/PDE-5I) tadalafil in treatment of LUTS due to BPH. These patients were reviewed at 1-, 3-, 6-month intervals with the above-mentioned parameters.

\section{RESULTS}

Of the 60 patients taken up for the study, 30 in each group, only 55 patients completed the study. (27 patients in alpha blockers group and 28 patients in PDE- 5 inhibitors group). Both groups were reviewed with mentioned parameters.

\section{CONCLUSIONS}

PDE-5 inhibitor (Tadalafil) should be preferred over alpha blockers in treating LUTS (Lower Urinary Tract Symptoms) due to BPH (Benign Prostatic Hyperplasia) as PDE -5 inhibitors are found to be more efficacious than alpha blocker with lesser incidences of side-effects.

\section{KEY WORDS}

BPH (Benign Prostatic Hyperplasia), LUTS (Lower Urinary Tract Symptoms), Alpha Blockers, Phosphodiesterase Type 5 Inhibitor, IPSS (International Prostatic Symptom Score), Uroflowmetry, PVR (Post Voidal Residual Urine Volume)
Corresponding Author: Dr. Sudhakaran Selvaraj, No. 1, Meeyanna Kadir Street, Vandavasi-604408,

Tamilnadu, India.

E-mail: tarugiffy@gmail.com

DOI: $10.14260 /$ jemds/2019/858

Financial or Other Competing Interests: None.

How to Cite This Article:

Selvaraj S, Sivalingam SK. The study of tabalafil and tamsulosin as monotherapy for lower urinary tract symptoms due to benign hyperplasia of prostate. J. Evolution Med. Dent. Sci. 2019;8(52):3968-3971, DOI: 10.14260/jemds/2019/858

Submission 28-02-2019,

Peer Review 05-12-2019,

Acceptance 11-12-2019,

Published 30-12-2019. 


\section{BACKGROUND}

BPH refers to proliferation of smooth muscle cells and epithelial cells mainly involving the transition zone of prostate gland. BPH presents with irritative and obstructive voiding symptoms. BPH causes BOO (Bladder Outlet Obstruction) by either static or dynamic mechanism. Static mechanism is by enlarged gland which can be cured by surgery. The second mechanism is dynamic which responds to pharmacological management especially with ALPHA blocker. Regardless of the exact proportion of epithelial to stromal cells in the hyperplastic prostate, there is no question that prostatic smooth muscle represents a significant volume of gland. Smooth muscle is one of the dominant cellular constituents in of BPH, accounting for $40 \%$ of the area density of hyperplastic prostate.(1) Active smooth muscle tone in the human prostate is regulated by adrenergic nervous system. Alpha 1a is the most abundant adrenergic receptor subtype present in human prostate. Moreover alpha 1 a receptor clearly mediates active tension in human prostatic smooth muscle. Alpha 1 blocker inhibits smooth muscle contraction and thus relieves dynamic component of BOO caused by BPH.(2) Tamsulosin is once daily administered alpha 1 blocker that exhibits some modest degree of selectivity for alpha 1 a receptor. Although the current medical therapy, alpha 1 blocker alone or in combination with 5 alpha reductase inhibitor, for BPH-LUTS is effective, it has potential side effects on sexual function like retrograde ejaculation/anejaculation. Incidence of abnormal ejaculation was $30 \%$ and erectile dysfunction was $6 \%$ in those patients treated with tamsulosin.(3)

BPH and ED are both occurring in the old aged men with incidence increasing as age increases further. Rationale for the use of PDE-5 inhibitor in the treatment of men with $\mathrm{BPH} /$ LUTS was initially based on demographic data showing the frequent occurrence of both ED and LUTS in men as they age. This raised the possibility of a common underlying mechanism at least contributing to both processes. Immunohistochemical studies showed that PDE-5 receptor is located in endothelial cells and smooth muscle cells of blood vessels of lower urinary tract. Blockage of these receptors leads to bladder neck relaxation. Mechanism of action of Tadalafil, a long acting PDE-5 inhibitor, for the treatment of men with BPH-LUTS is associated with NO/CGMP/protein kinase G pathway leading to smooth muscle relaxation in different lower urinary tract tissues in bladder, urethra, prostate and supporting vasculature beside increased blood perfusion to pelvic area and modulation of sensory stimuli from this area. However, in the studies so far available, there have been no significant changes in Qmax, suggesting that the effects of PDE-5I is alone may be either more focused on bladder muscle function than on prostatic tissue or that the effects are more profound on storage symptoms than on bladder outflow obstruction itself.

\section{METHODS}

We analysed 60 patients of BPH (Benign Prostatic Hyperplasia) with LUTS (Lower Urinary Tract Symptoms) with baseline parameters as international prostate symptom score (IPSS), QMAX (maximum urinary flow velocity), PVR (Post Voidal Residual urine volume), for a period of 6 months. They were divided in to two groups, one group receiving only alpha blockers, other group receiving only PDE -5 inhibitor (Phosphodiesterase type 5 inhibitor/PDE-5I) tadalafil in treatment of LUTS due to BPH. These patients were reviewed at 1, 3, 6 months interval with above mentioned parameters.

\section{Inclusion Criteria}

Male more than 45 years with LUTS due to BPH; that is male more than 45 years having either irritative (increased frequency, urgency, dysuria) or having obstructive LUTS (hesitancy, strain to void, thin stream of urine, intermittency)

\section{Exclusion Criteria}

Recent episodes of LUTS, patients on drugs, bladder calculi, bladder diverticula, chronic kidney disease, bilateral HUN, hematuria, h/o prostate surgery, h/o heart surgery.

\section{Study Type}

Controlled, Randomized, Observed, Prospective Study.

\section{Statistical Methods}

SPSS version 22 and electronic spreadsheets (MS-excel). The other data were analysed with chi-square test and fishers test.

\section{Study Tools}

- International prostate symptoms score (IPSS).

- Qmax (Maximum Urinary Flow Velocity) on uroflowmetry.

- $\quad$ Post void residual urine (PVR) (Ultra Sound).

- All these three parameters were recorded and reviewed at $1,3,6$ months.

\section{RESULTS}

Of the 60 patients studied (55) the results clearly show that PDE-5Is are better than alpha blockers in the treatment of LUTS due to BPH in this populations. (Alpha Blocker- GroupI, PDE-5I - Group - II).

\begin{tabular}{|c|c|c|c|c|}
\hline & Base Line & $1^{\text {st }}$ Month & $3^{\text {rd }}$ Month & $6^{\text {th }}$ Month \\
\hline \multicolumn{4}{|c|}{ Mean age } \\
\hline Group - I & 61.4 years & 61.4 years & 61.4 years & 61.4 years \\
Group - II & 63.5 years & 63.5 years & 63.5 years & 63.5 years \\
\hline \multicolumn{5}{|c|}{ Prostate size } \\
\hline Group - I & $56+/-6$ gms. & 56 gms. & $54+/-.7$ gms. & $54+/-.2$ gms. \\
Group - II & $53.7+/-7$ gms. & 53 gms. & $51+/-.5$ gms. & $50+/-.5$ gms. \\
\hline \multicolumn{5}{|c|}{ Table 1. Mean Age } \\
\hline
\end{tabular}

\begin{tabular}{|c|c|c|c|c|}
\hline & Base line & $1^{\text {st }}$ Month & $3^{\text {rd }}$ Month & $6^{\text {th }}$ Month \\
\hline \multicolumn{5}{|c|}{ PVR } \\
\hline Group - I & $86+/-12 \mathrm{ml}$ & $65+/-10 \mathrm{ml}$ & $50+/-6 \mathrm{ml}$ & $30+/-7 \mathrm{ml}$ \\
Group - II & $84+/-14 \mathrm{ml}$ & $70+/-9 \mathrm{ml}$ & $55+/-5 \mathrm{ml}$ & $25+/-5 \mathrm{ml}$ \\
\hline \multicolumn{5}{|c|}{ Table 2. PVR } \\
\hline
\end{tabular}

\begin{tabular}{c|c|c|c|c|}
\hline Group - I & $11+/-1.2 \mathrm{ml} / \mathrm{s}$ & $12+/-1.2 \mathrm{ml} / \mathrm{s}$ & $13+/-1 \mathrm{ml} / \mathrm{s}$ & $15+/-.7 \mathrm{ml} / \mathrm{s}$ \\
Group - II & $12+/-1 \mathrm{ml} / \mathrm{s}$ & $11.8+/-1.4 \mathrm{ml} / \mathrm{s}$ & $12.5+/-\mathrm{fd}$ & $15.2+/-1.5 \mathrm{~m} / \mathrm{s}$ \\
\hline
\end{tabular}
Table 3. Qmax 


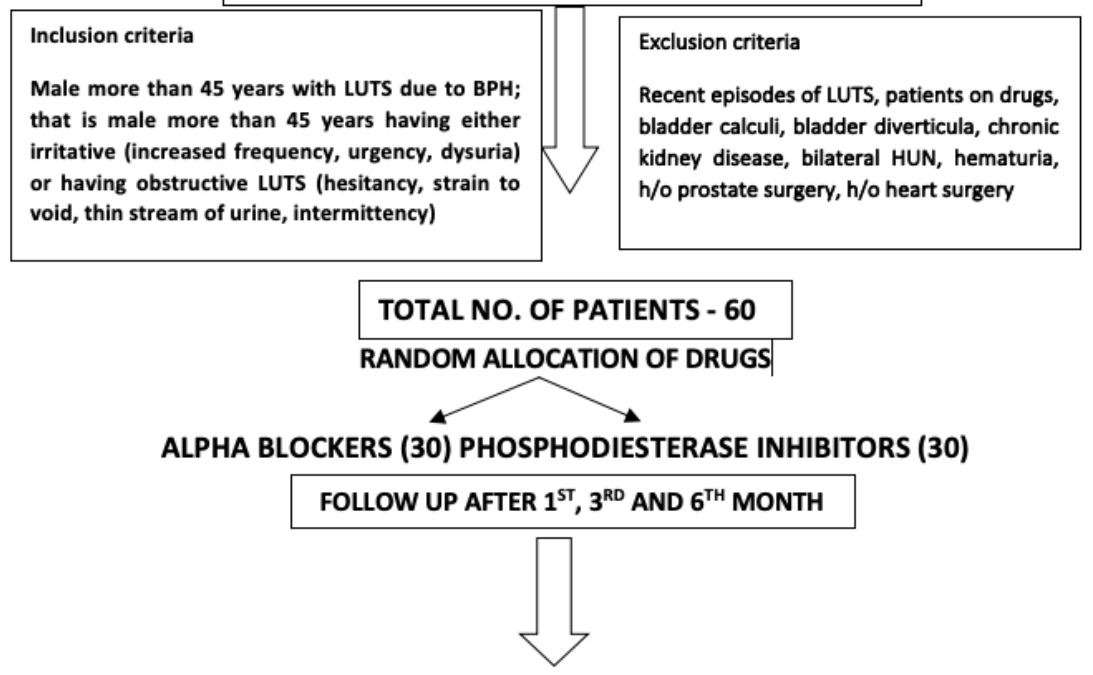

30 in each group only 55 patients completed the study. (27 patients in alpha blockers group, 28 patients in PDE - 5 inhibitors)

OUTCOME COMPARED IN TERMS OF

1. IPSS

2. QMAX

3. PVR

\begin{tabular}{|c|c|}
\hline Prostate Size & 'p' value \\
\hline $\begin{array}{c}\text { Group - I Alpha Blocker } \\
\text { Group - II PDE-5I }\end{array}$ & 0.15 \\
\hline \multicolumn{2}{|c|}{ Mean Age } \\
\hline PVR & 0.17 \\
\hline Group - I Alpha Blocker & 'p' value \\
Group - II PDE-5I & $<.005$ \\
\hline Qmax & 0.056 \\
\hline Group - I Alpha Blocker & 'p' value \\
\hline Group - II PDE-5I & $<=0.005$ \\
\hline \multicolumn{2}{|c|}{ Table 4. Qmax } \\
\hline
\end{tabular}

\section{DISCUSSION}

LUTS and ED are related conditions as age advances. The multinational survey of the ageing male (MSAM - 7) states that there is strong bond between age, sexual function, LUTS. PDE-5I are the first line drug for erectile dysfunction(4).FDA has been prescribing tadalafil ( $5 \mathrm{mg}$ ) for LUTS. This drug act by up regulation of no / cGMP pathway. They also reverse norepinephrine and endothelin induced prostate tissue contraction. By this way tension in the prostate tissue and capsule are reduced.(5) The alpha blockers act via alpha - 1 adrenergic receptors which are abundant in the bladder neck, stroma, prostate capsule. This dynamic part leads to obstruction to the urine outflow. So it is almost that BPH and ED are linked to some extent and share pathophysiological pathways. Tadalafil can be used for both LUTS and ED but to treat subclinical ED treatment is not approved. Patients with mild to moderate LUTS, tadalafil should be recommended as the drug of choice.

BPH/LUTS and ED both impact the quality of life of an individual patient. Alpha 1 blockers, which are standard of care for BPH/LUTS, have not shown consistent improvement in the erectile function, though there are few studies that report improvement. PDR-5 inhibitors, which are standard of care for treatment of ED, have been shown to cause a significant improvement in LUTS in patients with BPH in various studies, along with remarkable effect on erectile function, which has led to US-FDA approval of tadalafil for treatment of LUTS consistent with BPH with or without ED. After the first clinical report in 2002 of improvement in LUTS in men given sildenafil for their ED,(6) there has been explosion of interest in the role of PDE-5 inhibitors as a treatment of LUTS, and in particular, for the management of many men with both condition. Scientific basis is rapidly becoming stronger and there is now a good level 1 evidence from various clinical trials clearly showing improvements of LUTS after treatment with PDE-5 inhibitors.

The first RCT published to elucidate the impact of PDE-5 inhibitors was by Mcvary.(7) This was the first proper RCT, 12-week double blind placebo-controlled trial, showing improvement in both ED and IPSS score in PDE-5 inhibitors treated patients vs placebo. Second trial of Mcvary(7) was also double blind, placebo controlled, RCT evaluating the efficacy of Tadalafil. It included first a 4 wks. washout phase to reduce the placebo effect and reversion to mean phenomenon. Baseline IPSS score in Tadalafil arm improved from 17.5 to 13.3 while in placebo arm improved from 18.3 to 16.1 . This study showed that men in Tadalafil group were more likely to show a 3-point or greater improvement in IPSS by 12 wks than in men placebo group (60.9\% vs $42.7 \%$ ) indicating NNT (number needed to treat) of 5.5 Roehrborn(8) RCT, double blind placebo controlled trial for tadalafil also gave similar results. Further good quality studies have confirmed the 
benefits of PDE-5 inhibitors. Tadalafil has become the dominant agent because of its half-life and convenient $5 \mathrm{mg}$ daily dose and now has been licensed widely for prescription foe male LUTS. Analysis of pooled data of 1500 men in 4 international RCTs suggested that Tadalafil showed consistent efficacy compared with placebo( ${ }^{(9)}$ across multiple subgroups - for example, age, prostate volume, symptom severity.(10) Similar responses were shown in men with or without ED.(11)

\section{CONCLUSIONS}

Though BPH associated LUTS and ED are epidemiologically linked and share common pathophysiological pathways, there is an as yet undetermined link between BPH-LUTS and ED. There is now good Level 1 evidence of a beneficial effect of PDE-5I on urinary symptoms, though PDE-5I alone do not improve flow rates as the mechanisms of effect are still unclear and are subject of extensive research because so many other body systems are also affected. Our study concludes that PDE-5 inhibitor (Tadalafil) should be preferred over alpha blockers in treating LUTS due to BPH as PDE-5 inhibitors are found to be more efficacious than alpha blocker with lesser incidences of side-effects. It is likely that PDE-5I will be valuable, especially for men with BPH-LUTS and significant ED, though further data on safety and cost effectiveness is needed.

\section{REFERENCES}

[1] Shapiro E, Hartanto V, Lepor H. The response to alpha blockade in benign prostatic hyperplasia is related to the percent area density of prostate smooth muscle. Prostate 1992;21(4):297-307.
[2] Chapple C. Medical treatment for benign prostatic hyperplasia. BMJ 1992;304(6836):1198-9.

[3] Montorsi F. Profile of Silodosin. Eur Urol Suppl 2010;9:491-500.

[4] Rosen R, O'Leary M, Altwein J, et al. LUTS and male sexual dysfunction: the multi-national survey of the ageing male (MSAM-7). European Urology Supplements 2003;2(1):94.

[5] AUA Practice Guidelines Committee. AUA guideline on the management of BPH. Chap - 1: Diagnosis and treatment recommendations. J Urol 2003;170(2 Pt 1):530-47.

[6] Sairam K, Kulinskaya E, McNicholas TA, et al. Sildenafil influences lower urinary tract symptoms. BJU Int 2002;90(9):836-9.

[7] Mcvary KT, Monnig W, Camps JL Jr, et al. Sildenafil citrate improves erectile function and urinary symptoms in men with erectile dysfunction and lower urinary tract symptoms associated with benign prostatic hyperplasia: a randomized, double-blind trial. J Urol 2007;177(3):1071-7.

[8] Roehrborn CG. Benign prostatic hyperplasia: an overview. Rev Urology 2005;7 Suppl 9:S3-S14.

[9] Debruyne FM. Alpha blockers: are all created equal? Urology 2000;56(5 Suppl 1):20-2.

[10] Bortz WM 2nd, Wallace DH, Wiley D. Sexual function in 1,202 aging males: differentiating aspects. J Gerontol A Biol Sci Med Sci 1999;54(5):M237-41.

[11] Broderick GA, Brock GB, Roehrborn CG, et al. Effects of tadalafil on lower urinary tract symptoms secondary to benign prostatic hyperplasia in men with or without erectile dysfunction. Urology 2010;75(6):1452-8. 